\title{
Perinatal Development of Heart, Kidney, and Liver Mitochondrial Antioxidant Defense
}

\author{
ANGELO A. VLESSIS AND LEENA MELA-RIKER
}

Departments of Surgery and Biochemistry, Oregon Health Sciences University, Portland, Oregon 97201

\begin{abstract}
Development of the mitochondrial antioxidant defense system was studied to assess its potential role in the newborn mammal's tolerance to oxidative challenge and to gain insight into the fetal adaptation to a relatively hyperoxic adult environment. Isolated heart, kidney, and liver mitochondria from fetal, newborn, and adult guinea pigs were used. In situ function of the antioxidant enzymes was estimated in mitochondrial suspensions after the addition to selenite or tert-butyl hydroperoxide by determining $\mathrm{NAD}(\mathrm{P}) \mathrm{H}$ oxidation rates spectrophotometrically at 340-375 nm. Kidney and liver mitochondria from newborn animals were less susceptible to selenite and tert-butyl hydroperoxide-induced NAD(P)H oxidation. The pattern of change, however, varied widely with tissue type. Kidney mitochondria displayed the largest change with a 3- to 4fold increase in rate from the fetal to adult period. $\mathrm{NAD}(\mathrm{P}) \mathrm{H}$ oxidation rates in intact mitochondria did not correlate consistently with glutathione reductase and peroxidase activities in sonicated mitochondria suggesting in situ regulation by other endogenous factors. Immediately after birth, mitochondrial glutathione reductase and peroxidase activities dropped $38-50 \%$ and $50-70 \%$, respectively, in all tissues studied. Total glutathione content of heart and liver mitochondria did not change with age. Adult kidney mitochondrial glutathione, however, declined to $24 \%$ of fetal values. Mitochondrial superoxide dismutase activity increased $150-300 \%$ from the fetal to the adult period in all tissues studied. Perinatal changes in the mitochondrial antioxidant system and their relationship to mitochondrial calcium metabolism are discussed in terms of the newborn's resistance to oxidative stress. (Pediatr Res 26:220-226, 1989)
\end{abstract}

\section{Abbreviations}

GSH, reduced glutathione

GSSG, oxidized glutathione

SOD, manganese superoxide dismutase

tBOOH, tert-butyl hydroperoxide

Mammalian birth introduces a dramatic environmental change on the emerging organism. Altered circulation and oxygen availability necessitate adaptive changes in metabolism. Before birth, fetal oxygen tensions $\left(\mathrm{PaO}_{2}\right)$ are low $(25 \mathrm{~mm} \mathrm{Hg})$. After birth, average $\mathrm{PaO}_{2}$ rises (to $80-90 \mathrm{~mm} \mathrm{Hg}$ ) initiating the switch to a more aerobic metabolism (1-4). In the newborn

Received January 27, 1989; accepted May 8, 1989

Correspondence Angelo A. Vleissis, M.D., Ph.D., Department of Surgery, L223A, Oregon Health Sciences University, 3181 S.W. Sam Jackson Park Road, Portland, OR 97201.

Supported in part by a grant from the National Institutes of Health Grant GM33267 and the Medical Research Foundation of Oregon. period, rising tissue $\mathrm{PO}_{2}$ accompanies increased formation of reactive oxygen species which stimulate lipid peroxidation, as measured by ethane and pentane expiration $(5,6)$, as well as serum malondialdehyde (7) and lipoperoxide levels (8). As antioxidant defense systems develop, lipid peroxidation decreases to adult levels between $10-20 \mathrm{~d}$ of age $(7,8)$.

Despite increased lipid peroxidation at birth, newborn mammals are more resistant to a variety of oxidative challenges when compared to adult animals of the same species $(9,10)$. Although the biochemical mechanism of this tolerance remains unknown, the mitochondrial antioxidant system is likely to play a key role. When mitochondria metabolize oxidants, large quantities of $\mathrm{NAD}(\mathrm{P}) \mathrm{H}$ are consumed through glutathione dependent redox cycles $(11,12)$. An increase in the matrix $\mathrm{NAD}(\mathrm{P}) / \mathrm{NAD}(\mathrm{P}) \mathrm{H}$ ratio will induce $\mathrm{Ca}^{2+}$ efflux (12-14). Interestingly, isolated mitochondria from newborn animals are less susceptible to oxidantinduced $\mathrm{NAD}(\mathrm{P}) \mathrm{H}$ oxidation and $\mathrm{Ca}^{2+}$ release (15). Therefore, tolerance to oxidative stress in newborn animals may stem from differences in the mitochondrial antioxidant defense system.

Mitochondria generate reactive oxygen species at rates dependent on the surrounding $\mathrm{PO}_{2}(16,17)$. Under normal physiologic conditions, the respiratory chain produces superoxide radical and hydrogen peroxide $\left(\mathrm{H}_{2} \mathrm{O}_{2}\right)$, accounting for $1-4 \%$ of the total $\mathrm{O}_{2}$ consumed (18). Production rate increases linearly with $\mathrm{PO}_{2}(16,17)$. Therefore, a rise in average tissue $\mathrm{PO}_{2}$ at birth may enhance in vivo superoxide and $\mathrm{H}_{2} \mathrm{O}_{2}$ production by the mitochondrial respiratory chain.

Superoxide radicals and $\mathrm{H}_{2} \mathrm{O}_{2}$ liberated by the mitochondrial respiratory chain are reduced to $\mathrm{H}_{2} \mathrm{O}$ by antioxidant enzyme systems within the matrix. Superoxide radical can dismutate to $\mathrm{H}_{2} \mathrm{O}_{2}$ spontaneously or enzymatically (19). Glutathione peroxidase reduces $\mathrm{H}_{2} \mathrm{O}_{2}$ to $\mathrm{H}_{2} \mathrm{O}$ forming GSSG from GSH. Glutathione reductase then regenerates GSH from GSSG consuming $\mathrm{NAD}(\mathrm{P}) \mathrm{H}(20)$. Failure to remove $\mathrm{H}_{2} \mathrm{O}_{2}$ and superoxide increases the likelihood of forming hydroxyl radicals, highly reactive intermediates that can initiate the lipid peroxidative chain reaction (19). Conversely, effective removal of $\mathrm{H}_{2} \mathrm{O}_{2}$ will oxidize $\mathrm{NAD}(\mathrm{P}) \mathrm{H}$ and induce $\mathrm{Ca}^{2+}$ efflux (11-14). This type of efflux can uncouple oxidative phosphorylation via $\mathrm{Ca}^{2+}$ cycling involving the $\mathrm{Ca}^{2+} / \mathrm{H}^{+}$antiport and $\mathrm{Ca}^{2+}$-uniport systems $(21,22)$. In addition, oxidation of mitochondrial GSH and NAD(P)H may modulate substrate oxidations in mitochondria (23).

The development of antioxidant defense systems have been studied extensively in newborn animals, using tissue homogenates $(9,10,24-26)$. Little is known, however, about the development of the mitochondrial antioxidant defense system (25). This system is of paramount importance because: 1 ) mitochondria are a known source of reactive $\mathrm{O}_{2}$ species under normal physiologic conditions $(16-18), 2)$ the rate of mitochondrial superoxide radical and $\mathrm{H}_{2} \mathrm{O}_{2}$ generation increases linearly with $\left.\mathrm{PO}_{2}(16,17), 3\right)$ mitochondrial metabolism of peroxides can increase free intracellular $\mathrm{Ca}^{2+}(11,21)$ and deplete cellular ATP by inducing $\mathrm{Ca}^{2+}$ efflux and futile $\mathrm{Ca}^{2+}$ cycling, respectively, and 4 ) it may play a role in modulating substrate entry into oxidative pathways (23). 
The purpose of this study was to characterize the mitochondrial antioxidant defense system during the perinatal period and to assess its potential role in the newborn mammal's tolerance to oxidative stress. To do this, mitochondria from fetal, newborn and adult guinea pigs were studied using two approaches. First, the ability of intact, isolated mitochondria to reduce the oxidants selenite and $\mathrm{tBOOH}$ were determined. Second, NAD(P)H oxidation rates were compared to the mitochondrial glutathione reductase and peroxidase activities, as well as the endogenous substrate levels. Mitochondrial manganese-containing SOD was assayed as an indirect indicator of in vivo superoxide production.

\section{MATERIALS AND METHODS}

Animals. Topeka guinea pigs, bred and housed at this institution, were used as experimental animals. Term fetuses were obtained by cesarean section $63 \mathrm{~d}$ (full gestation) after a $1 \mathrm{wk}$ breeding period. Newborn animals in which the time of birth could not be accurately recorded were not used. Adult animals were maintained on ad libitum guinea pig food and water. Newborns were allowed to nurse until the time of sacrifice.

Mitochondrial preparations. Mitochondria were isolated as described by Mela et al. (4). Mitochondrial suspensions were analyzed for protein (27) and used to make the various determinations described below. Heart and kidney mitochondrial respiratory control ratios were consistently more than 10 ; those of the liver were more than 6.

Oxidation of mitochondrial $N A D(P) H$. NAD $(\mathrm{P}) \mathrm{H}$ oxidation was monitored kinetically at $340-375 \mathrm{~nm}$ in intact mitochondria using a Hitachi 557 dual wavelength spectrophotometer (13). Isolated mitochondria were suspended in $65 \mathrm{mM} \mathrm{KCl}, 125 \mathrm{mM}$ sucrose, $20 \mathrm{mM}$ Tris- $\mathrm{Cl}, 0.2 \mathrm{mM}$ Tris- $\mathrm{PO}_{4}, 10 \mu \mathrm{M}$ rotenone, and $2 \mathrm{mM}$ succinate at $\mathrm{pH}$ 7.4. $\mathrm{NAD}(\mathrm{P}) \mathrm{H}$ oxidation rates were calculated after addition of $500 \mu \mathrm{M}$ sodium selenite or $500 \mu \mathrm{M}$ $\mathrm{tBOOH}$. These concentrations elicit maximal oxidation rates $(12,15)$.

Nucleotide assay. Nucleotides were assayed according to Stocchi et al. (28). Mitochondria were suspended (at $25^{\circ} \mathrm{C}$ ) in $200 \mu \mathrm{L}$ of $120 \mathrm{mM} \mathrm{KCl}, 10 \mathrm{mM}$ Tris-Cl, $10 \mathrm{mM}$ Tris- $\mathrm{PO}_{4}, 5 \mathrm{mM}$ succinate, $10 \mu \mathrm{M}$ rotenone at $\mathrm{pH}$ 7.4. The suspension was alkalinized with $400 \mu \mathrm{L}$ of $0.5 \mathrm{M} \mathrm{KOH}$, vortexed for $15 \mathrm{~s}$ and cooled for $1 \mathrm{~min}$ on ice. The $\mathrm{pH}$ was adjusted to $6.5-7.0$ with $180 \mu \mathrm{L} 1 \mathrm{M} \mathrm{KH}_{2} \mathrm{PO}_{4}$ and the resulting solution was filtered (at $4^{\circ} \mathrm{C}$ ) using a Rainin $0.45-\mu \mathrm{m}$ filter. Nucleotides in the filtrate were separated on a RESOLVE $\mathrm{C}_{18-5}$ column $(3.9 \mathrm{~mm} \times 15 \mathrm{~cm})$ using the following solvent gradient: $0-9 \mathrm{~min}$, flow $0.8 \mathrm{~mL} / \mathrm{min}$ with $100 \% 0.1 \mathrm{M} \mathrm{KH}_{2} \mathrm{PO}_{4}$; $(\mathrm{pH} \mathrm{6.0)}$; 9-15 min, flow increased linearly to $1.3 \mathrm{ml} / \mathrm{min}$ and the mobile phase changed linearly to $2 \%$ methanol and $98 \% 0.1 \mathrm{M} \mathrm{KH}_{2} \mathrm{PO}_{4} ; 15-20 \mathrm{~min}$, mobile phase changed linearly to $10 \%$ methanol and $90 \% \quad 0.1 \mathrm{M} \mathrm{KH}_{2} \mathrm{PO}_{4}$. Nucleotides were detected at 254 and $340 \mathrm{~nm}$. Standard curves were constructed using external standards containing known quantities of nucleotides. Quantitation was based on peak area.

Glutathione reductase and peroxidase assays. Mitochondria were sonicated under buffered hypotonic $(60 \mathrm{mM} \mathrm{KCl}, 10 \mathrm{mM}$ Tris-Cl, and $10 \mathrm{mM}$ Tris- $\mathrm{PO}_{4}$ at $\mathrm{pH}$ 7.4) conditions in a saline ice bath and assayed immediately. For the reductase assay (29), $50-200 \mu \mathrm{L}$ aliquots of the sonicate were mixed with $800-950 \mu \mathrm{L}$ of $120 \mathrm{mM} \mathrm{KCl}, 10 \mathrm{mM}$ Tris- $\mathrm{Cl}, 10 \mathrm{mM}$ Tris- $\mathrm{PO}_{4}$, and $5 \mathrm{mM}$ GSSG at $\mathrm{pH} 7.4$. The reaction was started by adding $0.3 \mathrm{mM}$ NADPH and its disappearance was monitored kinetically at 340 $375 \mathrm{~nm}$. Glutathione peroxidase was assayed by the method of Tappel (30). Aliquots $(100-250 \mu \mathrm{L})$ of sonicate were mixed with $750-900 \mu \mathrm{L}$ of $120 \mathrm{mM} \mathrm{KCl}, 50 \mathrm{mM}$ Tris-Cl, $0.1 \mathrm{mM}$ EDTA, $0.25 \mathrm{mM}$ GSH, $0.3 \mathrm{mM}$ NADPH, and glutathione reductase $(2$ $\mathrm{U} / \mathrm{mL}$ ) at $\mathrm{pH}$ 7.4. The disappearance of NADPH was monitored kinetically after the addition of $1.2 \mathrm{mM}$ tBOOH. All measurements were done at $25^{\circ} \mathrm{C}$ in a Hitachi 557 dual wavelength spectrophotometer.

Glutathione assay. Total glutathione concentration was determined enzymatically using glutathione reductase and 5-5'-di- thiobis-2-nitrobenzoate (31). Mitochondria were sonicated as described above and frozen at $-70^{\circ} \mathrm{C}$ until assayed. Aliquots (100-200 $\mu \mathrm{L}$ ) of the thawed sonicate were mixed with $800-900$ $\mu \mathrm{L}$ of $120 \mathrm{mM} \mathrm{KCl}, 30 \mathrm{mM}$ Tris-Cl, $6.3 \mathrm{mM}$ EDTA, $1 \mathrm{mM}$

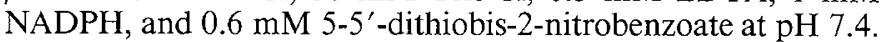
The reaction was initiated by addition of glutathione reductase $(4 \mathrm{U} / \mathrm{mL})$. Change in optical density at $412-540 \mathrm{~nm}$ was directly proportional to GSH concentration. Sample concentrations were calculated from a standard curve constructed with known concentrations of GSH.

$S O D$ assay. SOD in the sonicate was assayed by its ability to inhibit the reaction of nitroblue tetrazolium with superoxide anion radical $(32,33)$.

Ubiquinone assay. Heart, kidney, and liver mitochondrial suspensions were analyzed for ubiquinone by high pressure liquid chromatography using a RESOLVE $\mathrm{C}_{18-5}$ column as previously described (34).

Statistical analysis. Animals were grouped according to age and the results of the fetal and adult groups were compared individually with all other groups by ANOVA. Significant differences were confirmed using Dunnett's test. Additional information is provided in "Results" and the figure legends.

\section{RESULTS}

$N A D(P) H$ oxidation. Heart, kidney, and liver mitochondria from fetal and newborn animals were assayed for their ability to reduce selenite and $\mathrm{tBOOH}$. Figure 1 illustrates selenite and tBOOH induced oxidation of endogenous $\mathrm{NAD}(\mathrm{P}) \mathrm{H}$ in isolated mitochondria. Selenite catalyzes the nonenzymatic oxidation of GSH-forming GSSG (35). The metabolism of $\mathrm{tBOOH}$ involves glutathione peroxidase which uses $\mathrm{GSH}$ to reduce $\mathrm{tBOOH}$ to an alcohol, also forming GSSG. Once formed, GSSG is reduced by glutathione reductase consuming mitochondrial NADPH. NADH is also oxidized via the transhydrogenase reaction (20).

Age-related differences in mitochondrial $\mathrm{NAD}(\mathrm{P}) \mathrm{H}$ oxidation rates with selenite and $\mathrm{tBOOH}$ are shown in Figure 2. Fetal kidney mitochondria (day 0 ) exhibited low rates of selenite and $\mathrm{tBOOH}$ metabolism. Rates declined further during the first day and then rose steadily with age resulting in adult values that were 3- to 4-fold higher than fetal values. Heart mitochondria displayed low $\mathrm{NAD}(\mathrm{P}) \mathrm{H}$ oxidation rates with both selenite and tBOOH at all ages. Liver mitochondria displayed a much differ-

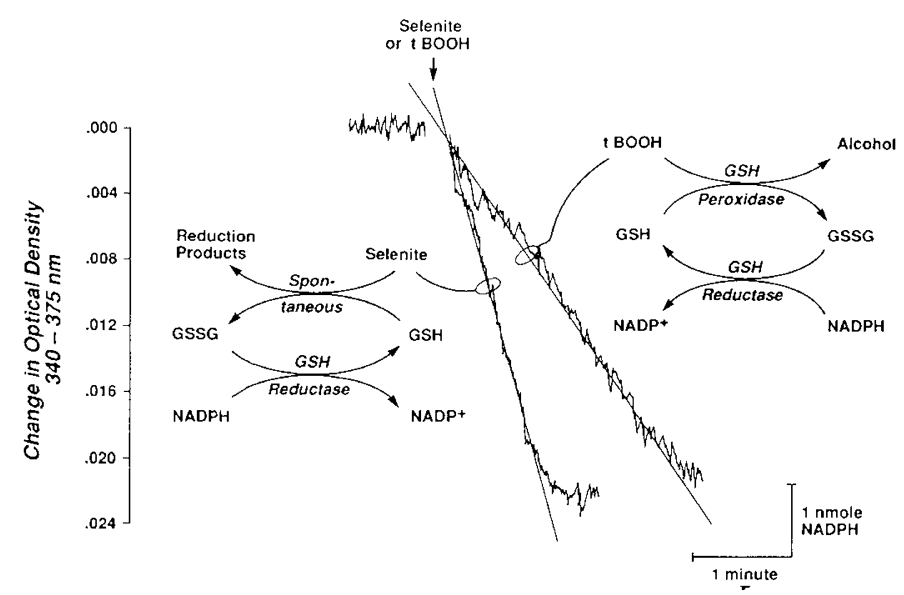

Fig. 1. Oxidation of endogenous $\mathrm{NAD}(\mathrm{P}) \mathrm{H}$ by selenite and $\mathrm{tBOOH}$ in isolated liver mitochondria from a 7.2-d-old animal. Mitochondria were suspended in buffered medium at $1.55 \mathrm{mg}$ protein $/ \mathrm{mL}$ and endogenous NAD(P)H was monitored kinetically at $340-375 \mathrm{~nm}$ as described in "Materials and Methods." Two tracings are shown superimposed in which either selenite $(500 \mu \mathrm{M})$ or $\mathrm{tBOOH}(500 \mu \mathrm{M})$ were added to initiate $N A D(P) H$ oxidation. Rates were calculated from the slope of a line drawn through each tracing. A simplified schematic of the metabolic pathways leading to $\mathrm{NAD}(\mathrm{P}) \mathrm{H}$ oxidation are shown for each oxidant. 
A
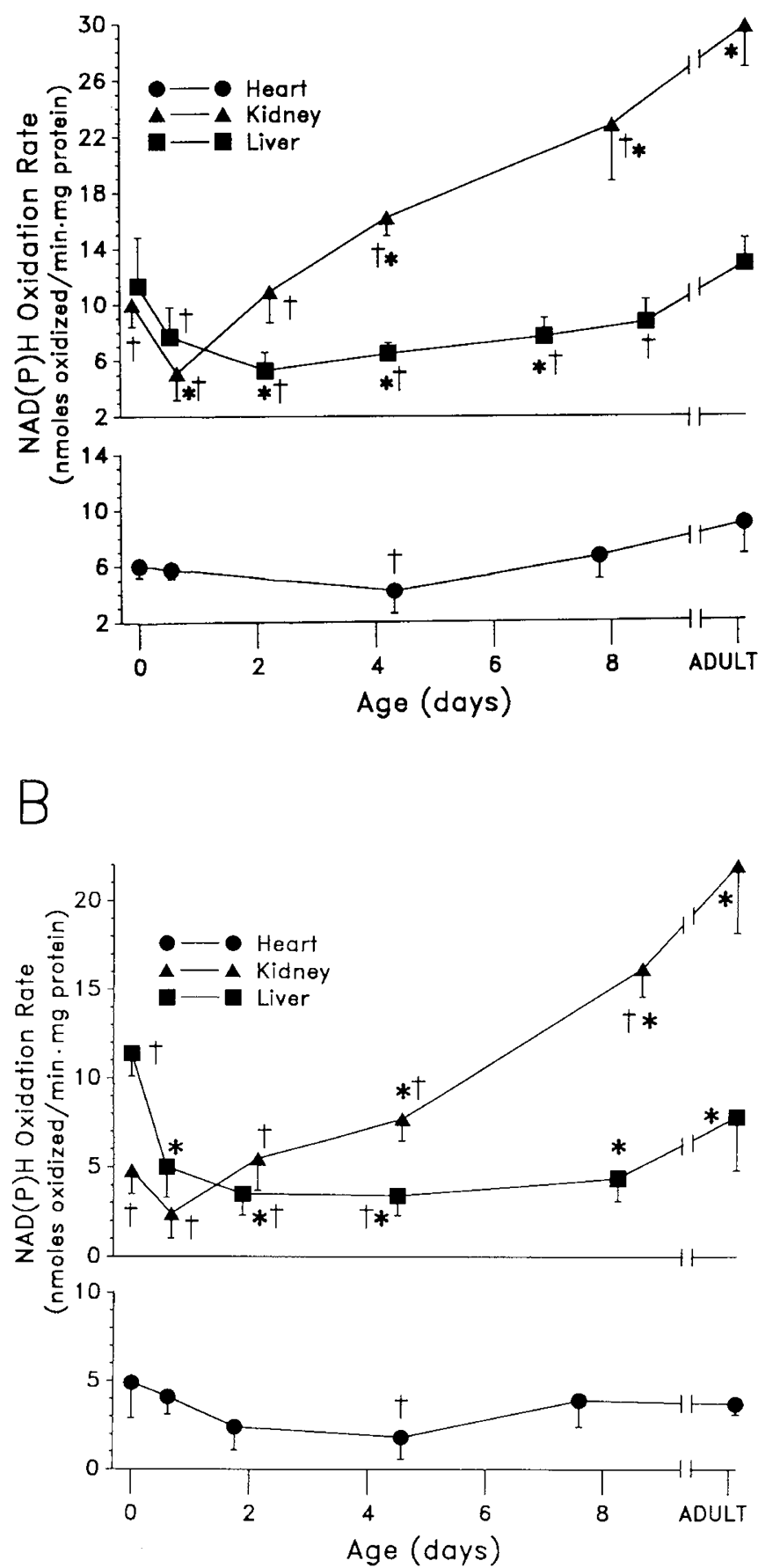

Fig. 2. Rate of $A$ selenite and $B \mathrm{tBOOH}$-induced NAD(P)H oxidation by isolated heart, kidney, and liver mitochondria from fetal (day 0 ), newborn, and adult animals. Rates were calculated as described in the legend to Figure 1. Each symbol depicts the mean NAD(P)H oxidation rate and age of each group. The bracket above or below each symbol includes one standard deviation from the mean. The $n$ values averaged five with a range of three to eight animals in each group. ${ }^{*}$ and $\dagger$ denotes a significant difference of at least $\alpha<0.05$ from the fetal and adult group, respectively.

ent pattern. Fetal NAD(P)H oxidation rates with selenite and tBOOH were high and declined rapidly during the first day. Rates with $\mathrm{tBOOH}$ remained low up to $8 \mathrm{~d}$ with adult rates persisting approximately $32 \%$ below fetal values. Rates with selenite were lowest at $d 2$ then increased slightly up to $d 8-9$; adult rates were comparable to those of the fetal group. Note that selenite-induced $\mathrm{NAD}(\mathrm{P}) \mathrm{H}$ oxidation rates were consistently higher than those obtained with $\mathrm{tBOOH}$ (Figs. 1 and 2), suggesting that glutathione peroxidase, and not GSSG reduction, was rate-limiting in $\mathrm{tBOOH}$ metabolism. To summarize, isolated mitochondria exhibited large age and tissue dependent differences in selenite and $\mathrm{tBOOH}$-induced $\mathrm{NAD}(\mathrm{P}) \mathrm{H}$ oxidation rates with similar patterns of change for both oxidants.

Glutathione reductase and peroxidase activities. To better understand the age-dependent differences in NAD(P)H oxidation, mitochondrial glutathione reductase and peroxidase activities were determined. Several important differences require emphasis. First, fetal mitochondria possessed the highest glutathione reductase activities in all tissues tested (Fig. $3 A$ ). Activity drops in all tissues during the first day with adult values remaining $15-$ $33 \%$ below fetal values. Kidney mitochondria exhibited higher glutathione reductase activities than liver or heart at all ages studied. Glutathione peroxidase activity of all mitochondria followed a similar age-dependent pattern, although significant tissue specific differences were evident (Fig. $3 B$ ). Most notably, mito-

A
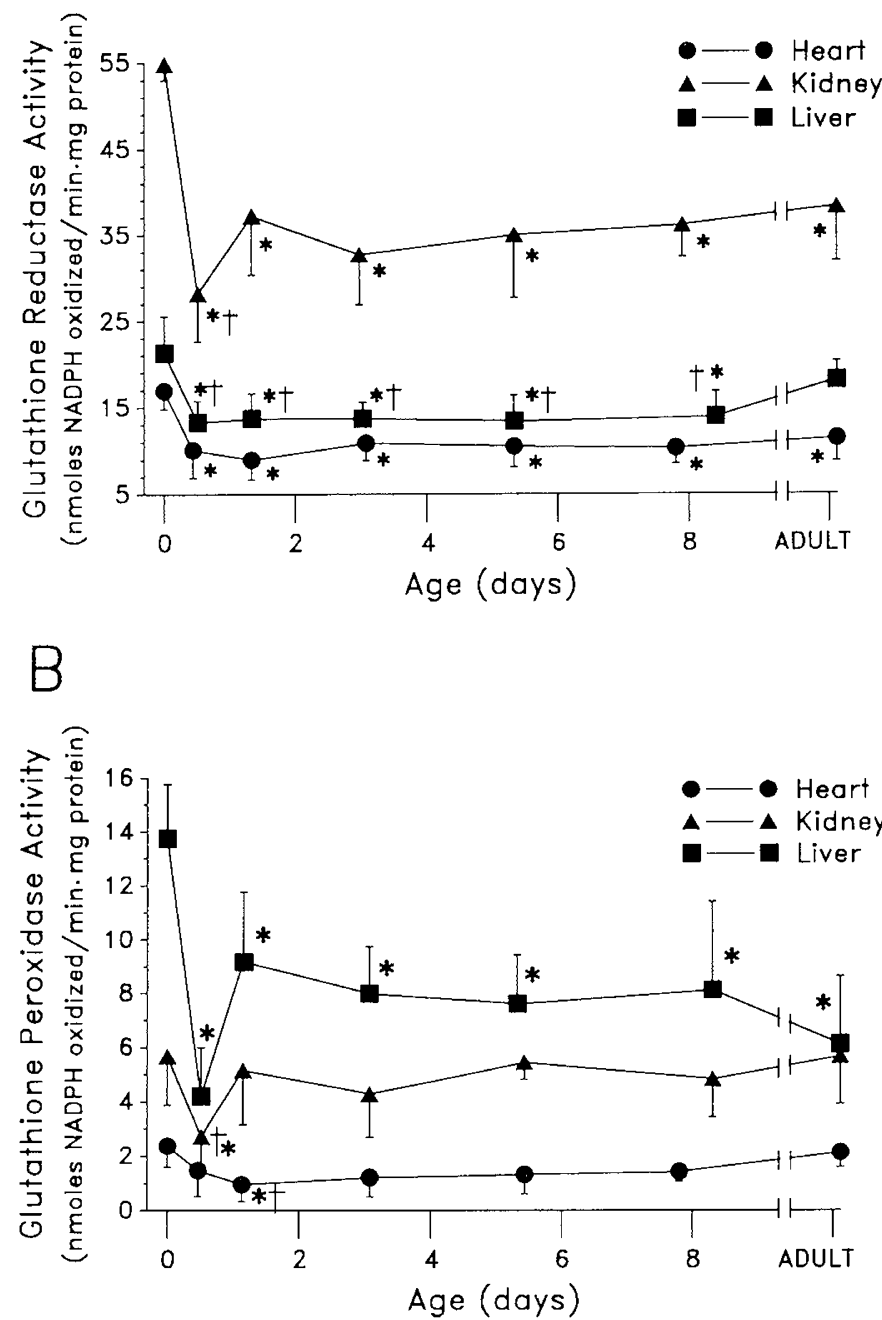

Fig. 3. Glutathione reductase $A$ and peroxidase $B$ activity in sonicated heart, kidney, and liver mitochondria from fetal (day 0), newborn, and adult animals. Each symbol depicts the mean enzyme activity and age for each group. The brackets above or below each symbol includes $1 \mathrm{SD}$ from the mean. The $n$ values averaged six with a range of three to nine animals in each group. ${ }^{*}$ and $\dagger$ denotes a significant difference of at least $\alpha<0.05$ from the fetal and adult group, respectively. 
chondrial glutathione peroxidase activities in fetal and newborn liver were higher than those of kidney or heart. Adult values in liver and kidney were similar, whereas the activities in heart mitochondria remained much lower.

An interesting paradox emerges when the mitochondrial glutathione reductase activities are compared with the seleniteinduced NAD (P) $\mathrm{H}$ oxidation rates in intact mitochondria. Inasmuch as selenite rapidly oxidizes GSH-forming GSSG, the rate of endogenous $\mathrm{NAD}(\mathrm{P}) \mathrm{H}$ oxidation with selenite should reflect mitochondrial glutathione reductase activity (Fig. 1). As expected, mitochondrial glutathione reductase activity (Fig. $3 A$ ) showed some correlation with the selenite-induced $\mathrm{NAD}(\mathrm{P}) \mathrm{H}$ oxidation rate (Fig. $2 A)$ in liver $(r=0.73)$ and heart $(r=0.81)$. In sharp contrast, glutathione reductase activities in kidney mitochondria do not correlate $(r=0.21)$ with the selenite-induced $\mathrm{NAD}(\mathrm{P}) \mathrm{H}$ oxidation rates. In fetal kidney mitochondria (Fig. $2 A)$, when $\mathrm{NAD}(\mathrm{P}) \mathrm{H}$ oxidation rates were low, glutathione reductase activities were highest (Fig. $3 A$ ). Conversely, in adult kidney mitochondria, glutathione reductase activities were $80 \%$ of fetal values and selenite-induced $\mathrm{NAD}(\mathrm{P}) \mathrm{H}$ oxidation rates were paradoxically $300 \%$ higher. Changes in glutathione reductase activities may explain age-related differences in seleniteinduced $\mathrm{NAD}(\mathrm{P}) \mathrm{H}$ oxidation rates in heart and liver but other factors are clearly involved in kidney mitochondria.

Another paradox exists between tBOOH-induced $\mathrm{NAD}(\mathrm{P}) \mathrm{H}$ oxidation rates in intact mitochondria and mitochondrial glutathione peroxidase activities. NAD $(\mathrm{P}) \mathrm{H}$ oxidation rates with tBOOH should reflect endogenous glutathione peroxidase activity. The peroxidase uses GSH to reduce tBOOH to an alcoholforming GSSG. GSSG is then reduced (via glutathione reductase) consuming $\mathrm{NAD}(\mathrm{P}) \mathrm{H}$ (Fig. 1). For heart mitochondria, this assumption appears to hold true; tBOOH-induced $\mathrm{NAD}(\mathrm{P}) \mathrm{H}$ oxidation rates (Fig. $2 B$ ) parallel endogenous glutathione peroxidase activity (Fig. $3 B$ ). Additionally, mitochondrial glutathione peroxidase activities in fetal kidney were $41 \%$ of values in fetal liver and, as expected, tBOOH-induced NAD(P)H oxidation rates in fetal kidney mitochondria were equally low (42\%) when compared to fetal liver mitochondria. This assumption fails when liver mitochondria from older animals are compared to those of kidney. Kidneys from animals more than $2 \mathrm{~d}$ of age have mitochondrial glutathione peroxidase activities consistently lower than those of liver (Fig. $3 B$ ), yet kidney mitochondria displayed paradoxically high $\mathrm{tBOOH}$-induced $\mathrm{NAD}(\mathrm{P}) \mathrm{H}$ oxidation rates; up to $280 \%$ of values in liver mitochondria. The rates of $\mathrm{tBOOH}$ metabolism in intact mitochondria reflect glutathione peroxidase activities for heart, as well as, fetal kidney and liver mitochondria. Other factors appear to regulate $\mathrm{tBOOH}$ metabolism in older $(>2$ d) kidney and liver mitochondria.

Mitochondrial glutathione concentrations. Inasmuch as the selenite and $\mathrm{tBOOH}$-induced $\mathrm{NAD}(\mathrm{P}) \mathrm{H}$ oxidation rates could be limited by substrate availability, the endogenous glutathione concentration of the isolated mitochondria were determined (Table 1). Heart and liver mitochondria show no consistent agerelated change in total glutathione content. In contrast, kidney mitochondria exhibited a steady decline in total glutathione as the age of the animal increases. Adult values for kidney mitochondria are $24 \%$ of fetal values, significantly lower than those of adult heart $(39 \%)$ or liver $(13 \%)$ mitochondria $(\alpha<0.025)$. Therefore, glutathione concentrations did not limit tBOOH or selenite-induced NAD $(\mathrm{P}) \mathrm{H}$ oxidation rates because adult kidney mitochondria had the lowest glutathione concentrations and yet exhibited the highest NAD(P)H oxidation rates.

Adenine and pyridine nucleotides. Several nucleotides are known inhibitors of glutathione peroxidase (36-38). NADPH and NADP ${ }^{+}$inhibit activity 30 to $55 \%$ at concentrations of 0.26 and $0.7 \mathrm{mM}$, respectively. Figure 4 displays the total NADP(H) concentrations in isolated heart, kidney, and liver mitochondria as a function of age. Note that liver mitochondria contained 2.5to 5.6-fold higher NADP $(\mathrm{H})$ levels than heart or kidney. ATP is also known to affect glutathione peroxidase activity, causing $30 \%$
Table 1. Total glutathione content of isolated kidney, heart, and liver mitochondria from animals of various ages*

\begin{tabular}{lccr}
\hline \multicolumn{1}{c}{ Age (d) } & \multicolumn{1}{c}{ Kidney } & Heart & \multicolumn{1}{c}{ Liver } \\
\hline Fetus (term) & $5.1 \pm 0.3(3)$ & $3.6 \pm 0.3(3)$ & $9.8 \pm 3.4(4)$ \\
$0.5 \pm 0.4$ & $4.0 \pm 1.6(7)$ & $4.2 \pm 0.9(6)$ & $10.6 \pm 2.4(7)$ \\
$1.1 \pm 0.1$ & $4.0 \pm 1.9(4)$ & $3.7 \pm 2.0(4)$ & $7.5 \pm 2.3(3)$ \\
$3.0 \pm 0.5$ & $3.6 \pm 0.5(3) \dagger$ & $4.5 \pm 1.2(4)$ & $6.9 \pm 2.4(5)$ \\
$5.2 \pm 0.3$ & $3.2 \pm 1.7(7)$ & $4.5 \pm 1.4(6)$ & $8.9 \pm 2.9(7)$ \\
$8.1 \pm 1.8$ & $1.7 \pm 0.8(5) \ddagger$ & $2.4 \pm 1.0(5)$ & $8.2 \pm 0.4(5)$ \\
Adult & $1.2 \pm 0.8(7) \ddagger$ & $3.2 \pm 1.6(6)$ & $9.7 \pm 1.6(6)$ \\
\hline
\end{tabular}

* Values are expressed as means $\pm 1 \mathrm{SD}$. Numbers in parentheses are the numbers of animals in each group.

$\dagger$ and $\ddagger$ denote a significant difference of $\alpha<0.01$ and $\alpha<0.001$ from the fetal group, respectively.

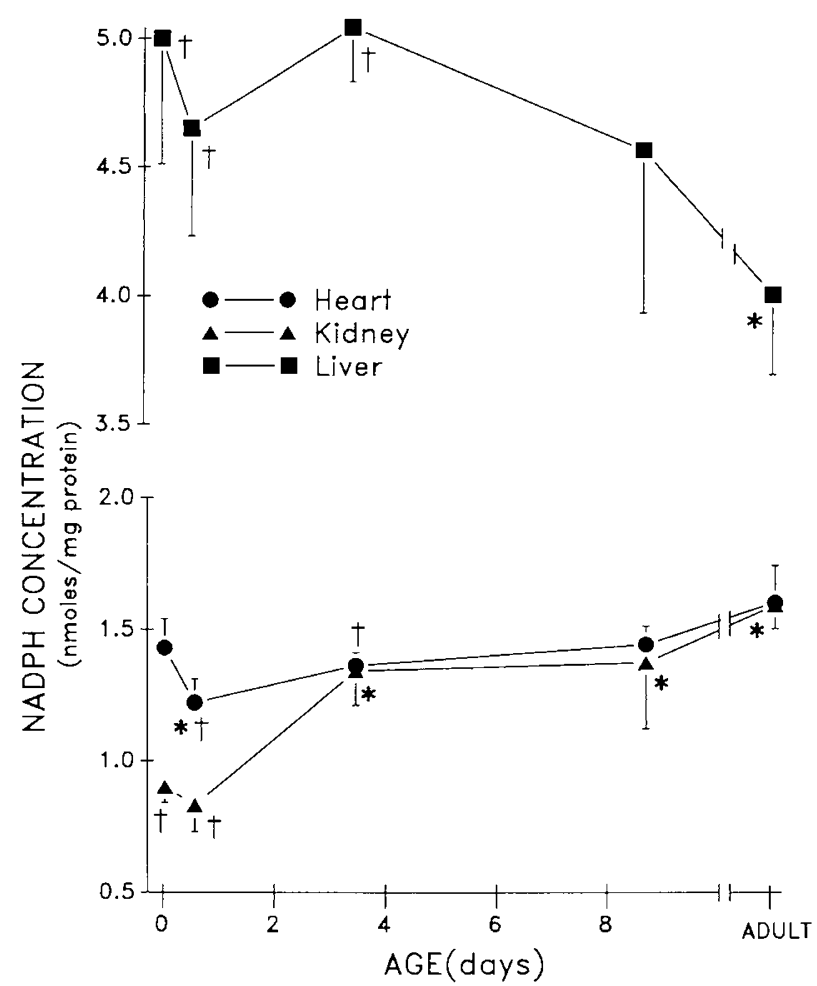

Fig. 4. $\mathrm{NADP}(\mathrm{H})$ concentration in isolated heart, kidney, and liver mitochondria from fetal (day 0), newborn, and adult animals. Each symbol depicts the mean NADP(H) concentration and age for each group. The bracket above or below each symbol includes 1 SD from the mean ( $n=$ four or five animals in each group). ${ }^{*}$ and $\dagger$ denotes a significant difference of at least $\alpha<0.05$ from the fetal and adult group, respectively.

inhibition at $0.7 \mathrm{mM}$ concentrations (36). Table 2 shows adenine nucleotide concentrations in isolated heart, kidney, and liver mitochondria as a function of age. Heart and liver showed significant increases in mitochondrial adenine nucleotides with age, however, no changes in kidney mitochondria were detected.

SOD activity. Heart, kidney, and liver SOD activities are significantly $(\alpha<0.01)$ higher in adults than in fetal animals (Fig. 5). Higher SOD activities suggest augmented superoxide radical formation by the mitochondrial respiratory chain. Inasmuch as the rate of mitochondrial superoxide generation increases linearly with ubiquinone concentration (17), the ubiquinone content of isolated heart, kidney and liver mitochondria from animals of various ages were determined. Animals were placed into groups according to age. Mitochondrial ubiquinone increased 1.6-, 2.0-, and 2.9-fold from the fetal to adult period in heart, kidney, and liver, respectively (data not shown). Figure 
Table 2. Adenine ribonucleotide content (ATP $+A D P+A M P)$ of isolated kidney, heart, and liver mitochondria from animals of various ages (values expressed as nmol/mg protein)*

\begin{tabular}{lccc}
\hline \multicolumn{1}{c}{ Age (d) } & Kidney & Heart & Liver \\
\hline Fetus (term) & $10.2 \pm 1.7(4)$ & $14.6 \pm 1.7(4)$ & $13.9 \pm 0.6(4)$ \\
$0.5 \pm 0.3$ & $10.8 \pm 1.4(4)$ & $14.6 \pm 1.6(4)$ & $17.8 \pm 0.7(4) \dagger$ \\
$3.2 \pm 0.3$ & $11.8 \pm 3.0(4)$ & $14.5 \pm 1.9(4)$ & $14.8 \pm 1.8(4)$ \\
$9.0 \pm 1.0$ & $10.3 \pm 0.8(5)$ & $14.1 \pm 1.4(5)$ & $15.5 \pm 1.3(5)$ \\
Adult & $12.1 \pm 1.1(4)$ & $22.1 \pm 1.3(4) \ddagger$ & $15.3 \pm 0.5(4)$ \\
\hline
\end{tabular}

* Values are expressed as means \pm 1 SD. Numbers in parentheses are the numbers of animals in each group.

$\dagger$ and $\ddagger$ denote a significant difference of $\alpha<0.025$ and $\alpha<0.001$ from the fetal group, respectively.

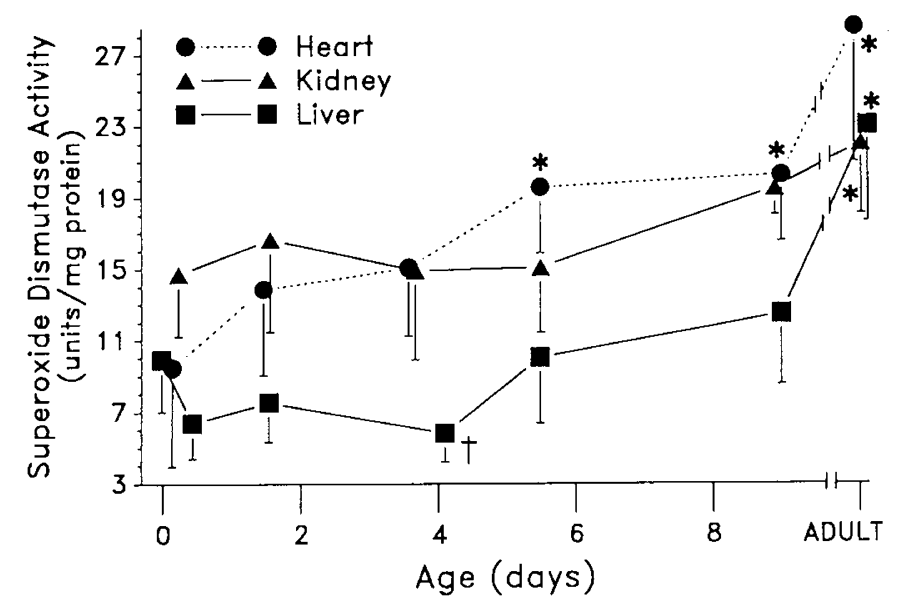

Fig. 5. Mitochondrial SOD activity in sonicated mitochondria from fetal (day 0), newborn, and adult animals. Each symbol depicts the mean SOD activity and age for each group. The bracket below each mean includes $1 \mathrm{SD}$. The $n$ values averaged five and ranged from three to seven animals in each group. ${ }^{*}$ and $\dagger$ denotes a significant difference of $\alpha<$ 0.01 and $<0.05$ respectively, from the fetal group.

6 shows the ubiquinone content versus SOD activity for each age group. The changes in ubiquinone correlate well with the changes in SOD activity in heart $(r=0.97)$ and kidney $(r=0.94)$ mitochondria. The correlation in liver mitochondria was insignificant $(r=0.52, \alpha=0.14)$.

\section{DISCUSSION}

Isolated mitochondria showed large age and tissue specific differences in both selenite and $\mathrm{tBOOH}$-induced NAD(P)H oxidation rates (Fig. 2). The similarity in the pattern of change for both oxidants is remarkable, however, the changes in NAD(P)H oxidation rate were not accompanied by corresponding alterations in antioxidant enzyme activities (Fig. 3). For example, oxidant-induced NAD(P)H oxidation rates in kidney mitochondria were 3- to 4-fold higher in the adult than in the fetus. This large difference in rates cannot be explained by elevated glutathione reductase or peroxidase activities. In fact, adult kidney mitochondrial glutathione reductase activities were $70 \%$ of fetal values, yet selenite-induced NAD(P)H oxidation rates were $300 \%$ higher. Similarly, kidney glutathione peroxidase activities were similar in the fetal and adult period despite $460 \%$ higher $\mathrm{tBOOH}-$ induced $\mathrm{NAD}(\mathrm{P}) \mathrm{H}$ oxidation rates in the adult. A similar discrepancy existed between $\mathrm{tBOOH}$-induced NAD(P)H oxidation rates and glutathione peroxidase activity in liver and kidney. Newborn $(>2$ d) and adult liver mitochondria had elevated or similar glutathione peroxidase activities when compared to kidney mitochondria of the same age. Intact kidney mitochondria, however, consistently display higher $\mathrm{NAD}(\mathrm{P}) \mathrm{H}$ oxidation rates

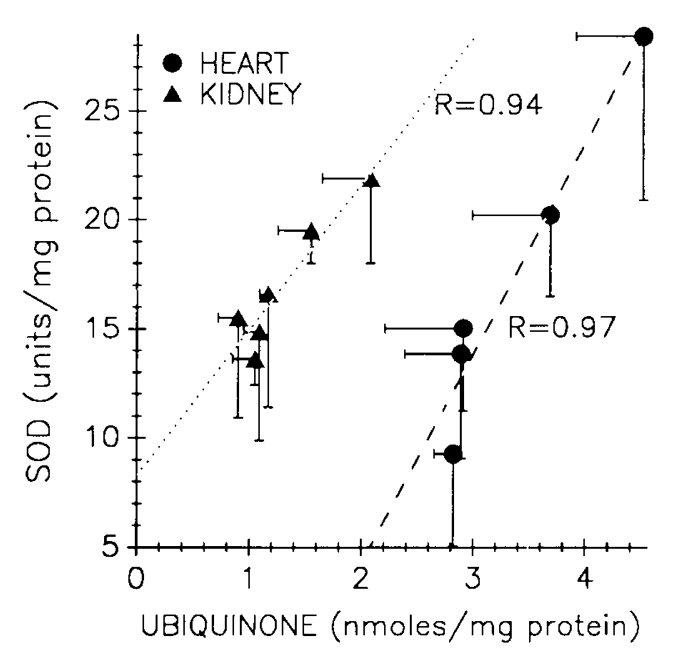

Fig. 6. Mitochondrial ubiquinone content versus SOD activity in heart and kidney mitochondria from animals of various ages. Animals were placed into groups according to animal age. Each symbol depicts the mean value obtained for each age group. The brackets below and left of each symbol include 1 SD from the mean SOD activity and ubiquinone content respectively. The $n$ values for each group averaged five and ranged from three to seven animals in each group. Both correlations are significant at $\alpha<0.002$.

than age-matched liver mitochondria. Therefore, mitochondrial glutathione reductase and peroxidase activities in sonicated mitochondria were not necessarily indicative of the antioxidant function of the intact organelle. Estimation of antioxidant function merely on the basis of enzyme activities in disrupted mitochondria may be misleading because other factors appear to be regulating the activities of these antioxidant defense enzymes in situ.

Several factors present in the mitochondrial matrix are known regulators of glutathione peroxidase and reductase activity. NADPH and NADP ${ }^{+}$inhibit glutathione peroxidase activity $30-$ $50 \%$ at 0.26 and $0.7 \mathrm{mM}$ concentrations, respectively $(36,37)$. Figure 4 reveals 2.5 - 5.6 fold higher $\mathrm{NAD}(\mathrm{P}) \mathrm{H}$ levels in liver mitochondria than those of kidney or heart. This corresponds to matrix NAD(P)H concentrations of 4.2 to $5.0 \mathrm{mM}$ in liver mitochondria, assuming a matrix volume of $1 \mu \mathrm{L} / \mathrm{mg}$ mitochondrial protein. Therefore, $\mathrm{NAD}(\mathrm{P}) \mathrm{H}$ inhibition of glutathione peroxidase in situ may be responsible for lower $\mathrm{tBOOH}$-induced $\mathrm{NAD}(\mathrm{P}) \mathrm{H}$ oxidation rates despite higher glutathione peroxidase activity in older ( $>2$ d) liver versus kidney mitochondria. Incubation of glutathione reductase with NADPH or NADH causes reversible inactivation of the enzyme. This type of inhibition may have an important regulatory role $(20,29)$. Adenine ribonucleotides are competitive inhibitors of glutathione peroxidase with increased hydroperoxide levels enhancing the inhibitory effect (36). No correlation, however, was found between the agerelated changes in mitochondrial ATP content (Table 2) and tBOOH-induced $\mathrm{NAD}(\mathrm{P}) \mathrm{H}$ oxidation rates. Coenzyme $\mathrm{A}$ is also a potent inhibitor of glutathione peroxidase with a $\mathrm{K}_{\mathrm{i}}$ of $<5 \mu \mathrm{M}$. Binding the sulfhydryl group of coenzyme A reduces the inhibitory effectiveness 6 -fold (37). All these potential regulators are present within the mitochondria at concentrations known to affect the enzymatic rate. Therefore, mitochondrial antioxidant function, estimated solely by enzyme activities in disrupted mitochondria, should be interpreted with caution.

SOD activities were higher in adult heart, kidney, and liver mitochondria when compared to the fetus (Fig. 5) suggesting heightened superoxide radical production in adult mitochondria. Similar increases in rat brain mitochondrial SOD after birth have been described (25). Two known factors that influence the rate of superoxide formation by mitochondria require emphasis. 
First, the rate of superoxide formation increases linearly with the $\mathrm{PO}_{2}$ at the mitochondrial inner membrane $(16,17)$. This depends, in part, on changes in organ blood flow and incoming $\mathrm{PaO}_{2}$, factors that vary with perinatal age and the tissue in question. Second, the concentration of mitochondrial ubiquinone, the predominate site of superoxide radical formation (17), increases in heart, kidney, and liver postbirth (see "Results"). Assuming the $\mathrm{PO}_{2}$ at the inner membrane does not decrease, mitochondrial superoxide formation should increase with ubiquinone concentration. In fact, mitochondrial SOD activity correlates well with ubiquinone concentration in heart and kidney (Fig. 6). The rise of mitochondrial SOD from the fetal to adult period is a complex phenomenon that may suggest heightened mitochondrial superoxide radical generation. The etiology remains speculative, however, the rise in heart and kidney mitochondrial ubiquinone may lead to elevated SOD activity indirectly by increasing the rate of superoxide radical formation (17). In liver mitochondria, the lack of correlation between ubiquinone concentration and SOD activity suggests that other factors (e.g. $\mathrm{PO}_{2}$, other sources of superoxide, translobular heterogeneity) may be operative in liver.

Selenite or tBOOH-induced oxidation of endogenous $\mathrm{NAD}(\mathrm{P}) \mathrm{H}$ in intact mitochondria may be a more reliable indicator of mitochondrial antioxidant function than determination of enzyme activities in disrupted mitochondria. Nevertheless, other yet unstudied pathways may interfere with interpretation of data obtained by this method. In certain cell types, GSSG formed during oxidant metabolism can be actively extruded from the cell (40). Although preliminary results in our laboratory are negative, a similar GSSG transport system may exist in mitochondria which could compete with glutathione reductase for GSSG, thereby decreasing the NAD(P)H oxidation rate. In addition, succinate with rotenone, used as substrate in these experiments, may give falsely low $\mathrm{NAD}(\mathrm{P}) \mathrm{H}$ oxidation rates in the presence of $\mathrm{NADP}^{+}$-malate dehydrogenase. Heart mitochondria are known to contain substantial levels of this enzyme (41), possibly accounting for the low rates of oxidant-induced $\mathrm{NAD}(\mathrm{P}) \mathrm{H}$ oxidation (Fig. 2). $\mathrm{NADP}^{+}$-malic enzyme may also be an important source of reducing equivalents necessary for mitochondrial oxidant detoxification. The significance of mitochondrial GSSG transport and NADP ${ }^{+}$-malate dehydrogenase activity in the mitochondrial antioxidant defense system are currently under investigation.

Mitochondrial antioxidant function may provide resistance to oxidative stress in the newborn period by stabilizing the mitochondrial $\mathrm{Ca}^{2+}$ pool. Mitochondria continually cycle $\mathrm{Ca}^{2+}$ through separate uptake and efflux systems. Under normal conditions, a low steady-state extramitochondrial $\mathrm{Ca}^{2+}$ concentration is maintained against a continual slow efflux by an active $\mathrm{Ca}^{2+}$ uniport (21). Oxidation of mitochondrial $\mathrm{NAD}(\mathrm{P}) \mathrm{H}$, by a variety of substances, accelerates $\mathrm{Ca}^{2+}$ efflux, possibly through activation of a $\mathrm{Ca}^{2+} / \mathrm{H}^{+}$antiport $(14,22)$. Efflux initiates a futile $\mathrm{Ca}^{2+}$ cycle as the uniport system actively takes up released $\mathrm{Ca}^{2+}$ (42). ATP levels drop because $\mathrm{Ca}^{2+}$ uptake continues at the expense of ATP production (43). If necessary, extramitochondrial ATP may also be hydrolyzed to maintain mitochondrial $\mathrm{Ca}^{2+}$ uptake (42). During the newborn period, the mitochondrial antioxidant system displayed significantly lower oxidant-induced $\mathrm{NAD}(\mathrm{P}) \mathrm{H}$ oxidation rates than those of adult animals (Fig. 2). Lower $\mathrm{NAD}(\mathrm{P}) \mathrm{H}$ oxidation should prevent mitochondrial $\mathrm{Ca}^{2+}$ efflux. To support this, liver mitochondria from newborn animals are indeed less susceptible to oxidant-induced $\mathrm{Ca}^{2+}$ efflux than those of adult animals (15). The ability of the mitochondrial antioxidant system to resist $\mathrm{NAD}(\mathrm{P}) \mathrm{H}$ oxidation in the newborn period may provide tolerance to oxidative challenge by stabilizing the mitochondrial $\mathrm{Ca}^{2+}$ pool.

This report characterizes, for the first time, the mitochondrial antioxidant defense system during perinatal development in three important tissues. The results demonstrate that: $l$ ) intact mitochondria from newborn animals are less susceptible than those of adults to oxidant-induced $\mathrm{NAD}(\mathrm{P}) \mathrm{H}$ oxidation. Inasmuch as mitochondrial $\mathrm{Ca}^{2+}$ efflux has been linked to oxidantinduced NAD(P)H oxidation, the newborn's resistance to oxidant-induced $\mathrm{NAD}(\mathrm{P}) \mathrm{H}$ oxidation, and thus $\mathrm{Ca}^{2+}$ efflux, may underlie their tolerance to hyperoxia $(9,10)$ and other exogenous oxidants (15). 2) Age- and tissue-specific differences in mitochondrial glutathione reductase do exist. In the term fetus, mitochondrial glutathione reductase is high. Activity drops during the first day in all tissues studied with adult values remaining below those of the fetus. Mitochondrial glutathione peroxidase shows a similar age-dependent pattern with a significant decline in activity occurring post-birth in all tissues. 3) Mitochondrial SOD activity is increased in adult mitochondria as compared to fetal or newborn animals. 4) NAD(P)H oxidation rates in intact mitochondria do not consistently correlate with glutathione reductase and peroxidase activities in disrupted mitochondria. These findings suggest involvement of additional endogenous regulatory factors in antioxidant-related responses in situ.

Acknowledgment. The authors thank Debbie Nelson for her help in the preparation of the manuscript.

\section{REFERENCES}

1. Fischer DJ, Heymann MA, Rudolph AM 1982 Regional myocardial blood flow and oxygen delivery in fetal, newborn and adult sheep. Am J Physiol 243:H729-H731

2. Harris AP, Sendak MJ, Donham RT 1986 Changes in arterial oxygen immediately after birth in the human neonate. J Pediatrics 109:117-119

3. Itskovitz J, Goetzman BW, Roman C, Rudolph AM 1984 Effects of fetalmaternal exchange transfusion on fetal oxygenation and blood flow distribution. Am J Physiol 247:H655-H660

4. Mela L, Goodwin CW, Miller LD 1975 Correlations of mitochondrial cytochrome concentrations and activity to oxygen availability in the newborn. Biochem Biophys Res Commun 64:384-390

5. Wispe RJ, Bell EF, Roberts RJ 1985 Assessment of lipid peroxidation in newborn infants and rabbits by measurements of expired ethane and pentane: influence of parenteral lipid infusion. Pediatr Res 19:374-379

6. Wispe JR, Knight M, Roberts RJ 1986 Lipid peroxidation in newborn rabbits: effects of oxygen, lipid emulsion, and Vitamin E. Pediatr Res 20:505-510

7. McCarthy K, Bhogal M, Naudi M, Hart D 1984 Pathogenic factors in bronchopulmonary dysplasia. Pediatr Res 18:483-488

8. Yoshioka T, Motoyama H, Yamasaki F, Noma J 1982 Lipid peroxidation and its protective mechanism during developmental stage in rat. Acta Obstet Gynaecol Jpn 34:966-970

9. Sosenko IRS, Frank L 1987 Guinea pig lung development: antioxidant enzymes and premature survival in high $\mathrm{O}_{2}$. Am J Physiol 252:R693-R698

10. Yam J, Frank L, Roberts RJ 1978 Oxygen toxicity: comparison of lung biochemical responses in neonatal and adult rats. Pediatr Res 12:115-119

11. Beatrice MC, Stiers DL, Pfeiffer DR 1984 The role of glutathione in retention of $\mathrm{Ca}^{2+}$ by liver mitochondria. J Biol Chem 259:1279-1287

12. Lotscher HR, Winterhalter KH, Carafoli E, Richter C 1980 Hydroperoxideinduced loss of pyridine nucleotides and release of calcium from rat liver mitochondria. J Biol Chem 255:9925-9930

13. Lehninger AL, Vercesi A, Bababunmi EA 1978 Regulation of $\mathrm{Ca}^{2+}$ release from mitochondria by the oxidation reduction state of pyridine nucleotides. Proc Natl Acad Sci USA 75:1690-1694

14. Nicholls DG, Brand MD 1980 The nature of calcium ion efflux induced in rat liver mitochondria by the oxidation of endogenous nicotinamide nucleotides. Biochem J 188:113-118

15. Vlessis AA, Mela-Riker L 1987 Selenite-induced NAD(P)H oxidation and calcium release in isolated mitochondria: relationship to in vivo toxicity. Mol Pharmacol 31:643-646

16. Turrens JF, Freeman BA, Levitt JG, Crapo JD 1982 The effect of hyperoxia on superoxide production by lung submitochondrial particles. Arch Biochem Biophys 217:401-410

17. Boveris A 1977 Mitochondrial production of superoxide radical and hydrogen peroxide. In: Reivich M, Coburn R, Lahiri S, Chance B (eds) Tissue Hypoxia and Ischemia. Plenum Press, New York, pp 67-81

18. Chance B, Sies H, Boveris A 1979 Hydroperoxide metabolism in mammalian organs. Physiol Rev 59:527-605

19. Fridovich I 1982 Superoxide dismutase in biology and medicine. In: Autor AP (ed) Pathology of Oxygen. Academic Press, Inc., New York, pp 1-17

20. Reed DJ 1986 Regulation of reductive processes by glutathione. Biochem Pharmacol 35:7-13

21. Fiskum G, Lehninger AL 1982 Mitochondrial regulation of intracellular calcium. In: Cheung WY (ed) Calcium and Cell Function, Vol II. Academic Press, Inc., New York, pp 39-80

22. Frei B, Winterhalter KH, Richter C 1985 Quantitative and mechanistic aspects of hydroperoxide-induced release of $\mathrm{Ca} 2+$ from rat liver mitochondria. Eur J Biochem 149:633-639 
23. Sies H, Moss KM 1978 A role of mitochondrial glutathione peroxidase in modulating mitochondrial oxidations in liver. Eur $\mathrm{J}$ Biochem 84:377-383

24. Frank L, Groseclose EE 1984 Preparation for birth into an $\mathrm{O}_{2}$-rich environment: the antioxidant enzymes in the developing rat lung. Pediatr Res 18:240-244

25. Mavelli I, Rigo A, Federico R, Ciriolo MR, Rotilio G 1982 Superoxide dismutase, glutathione peroxidase, and catalase in developing rat brain. Biochem J 204:535-540

26. Tanswell KA, Freeman BA 1984 Pulmonary antioxidant enzyme maturation in fetal and neonatal rat I. Developmental profiles. Pediatr Res 18:584-587

27. Lowry OH, Rosebrough NJ, Farr AL, Randall RJ 1951 Protein measurement with the folin phenol reagent. J Biol Chem 193:265-275

28. Stocci V, Cucchiarini L, Magnani M, Chiarantini L, Palma P, Crescentini G 1985 Simultaneous extraction and reverse-phase high performance liquid chromatographic determination of adenine and pyridine nucleotides in human red blood cells. Anal Biochem 146:118-124

29. Podrazky V, Stevens FS 1984 Reversible inhibition by its coenzyme as a source of error in glutathione reduction assays. Clin Chim Acta 137:349-354

30. Tappel AL 1984 Glutathione peroxidase and hydroperoxides. Methods Enzymol 105:506-513

31. Griffith OW 1980 Determination of glutathione and glutathione disulfide using glutathione reductase and 2-vinyl pyridine. Anal Biochem 106:207-212

32. Flohe L, Otting F 1984 Superoxide dismutase assays. Methods Enzymol 105:93-104

33. Winterbourn CC, Hawkins RE, Brian M, Carrell RW 1975 The estimation of red cell superoxide dismutase activity. J Lab Clin Med 85:337-342

34. Okamoto T, Fukui K, Nakamoto M, Okishio T, Yamagami T, Kanamori N, Kishi H, Hiraoka E 1985 High performance liquid chromatography of coenzyme Q-related compounds and its application to biological materials. J Chromatogr 342:35-46

35. Tsen CC, Tappel AL 1958 Catalytic oxidation of glutathione and other sulfhydryl compounds by selenite. J Biol Chem 233:1230-1232

36. Little C, Olinescu RM, Reid KG, O'Brien PJ 1970 Properties and regulation of glutathione peroxidase. J Biol Chem 245:3632-3636

37. Little C, Olinescu RM, O'Brien PJ 1970 Inhibition of glutathione peroxidase by coenzyme A. Biochem Biophys Res Commun 41:287-293

38. Zakowski JJ, Tappel AL 1978 Purification and properties of rat liver mitochondrial glutathione peroxidase. Biochem Biophys Acta 526:65-76

39. Lopez-Barea J, Lee CY 1979 Mouse-liver glutathione reductase. Purifications, kinetics, and regulations. Eur J Biochem 98:487-499

40. Sies H, Akerboom TPM 1984 Glutathione disulfide (GSSG) efflux from cells and tissues. Methods Enzymol 105:445-451

41. Andres A, Satrustegui J, Machado A 1980 Development of NAD(P)H producing pathways in rat heart. Biochem J 186:799-803

43. Mela L 1977 Mechanism and physiological significance of calcium transport across mammalian mitochondrial membranes. In: Bronner F, Kleinzeller A (eds) Current Topics in Membranes and Transports, Vol 9. Academic Press, Inc, New York, pp 321-362

42. Vlessis AA, Mela-Riker L 1989 Potential role of mitochondrial calcium metabolism in reperfusion injury. Am J Physiol (in press). 